\title{
Natural ventilation systems to enhance sustainability in buildings: a review towards zero energy buildings in schools
}

\author{
Maite Gil-Baez ${ }^{1, *}$, Ángela Barrios-Padura ${ }^{1}$, Marta Molina-Huelva ${ }^{1}$, and Ricardo \\ Chacartegui $^{1}$ \\ ${ }^{1}$ University of Seville, Avda. Reina Mercedes n², 41012 Seville, Spain
}

\begin{abstract}
European regulations set the condition of Zero Energy Buildings for new buildings since 2020, with an intermediate milestone in 2018 for public buildings, in order to control greenhouse gases emissions control and climate change mitigation. Given that main fraction of energy consumption in buildings operation is due to HVAC systems, advances in its design and operation conditions are required. One key element for energy demand control is passive design of buildings. On this purpose, different recent studies and publications analyse natural ventilation systems potential to provide indoor air quality and comfort conditions minimizing electric power consumption. In these passive systems are of special relevance their capacities as passive cooling systems as well as air renovation systems, especially in high-density occupied spaces. With adequate designs, in warm/mild climates natural ventilation systems can be used along the whole year, maintaining indoor air quality and comfort conditions with small support of other heating/cooling systems. In this paper is analysed the state of the art of natural ventilation systems applied to high density occupied spaces with special focus on school buildings. The paper shows the potential and applicability of these systems for energy savings and discusses main criteria for their adequate integration in school building designs.
\end{abstract}

\section{Introduction}

Energy consumption in EU due to buildings operation is $40 \%$ of the global energy consumption, and its main fraction is due to HVAC systems operation with $60 \%$. To accomplish with EU regulations [1] and the Zero Energy Buildings [2] is required a drastic reduction of this energy consumption for indoor conditioning. Different recent studies and publications analyse natural ventilation systems potential to provide indoor air quality and comfort conditions with minimum electric power consumption. As an example of the interest of this subject, in last ten years more than ninety studies of natural ventilation systems are recorded in Scopus.

\footnotetext{
${ }^{*}$ Corresponding author: gmaitegil@gmail
} 
In this paper is analysed the state of the art of natural ventilation systems applied to high density occupied spaces with special focus on the educational sector, showing the potential and applicability of these systems for energy savings under different classification criteria. It is structured in four sections: firstly design and demand profiles in schools; then indoor environmental quality (IEQ) is analysed; in third section actual situation is exposed and in the last section main conclusions are presented.

\section{School design and demand profiles in schools}

One of the most important groups of civil buildings is composed by schools. In the Mediterranean region there are more than 80000 schools [3], being a big energy consumer. This sector consumes $4 \%$ of the energy in the commercial sector in Spain [4].

R\&D activity in school buildings is intense with relevant international R\&D projects., $[3,5]$. The school building segment is unique in the building domain since it has specific typologies, users and usage patterns, energy infrastructures, energy uses and functions. Specific characteristics of schools are the next:

a) Schools design is based in a rational organization of the spaces. Classrooms are usually grouped and there is a corridor to access them. This situation is presented in figure 1 . In addition, classrooms have wide dimensioned windows in order to allow natural illumination of the space, as well as there are other high windows to corridor to be used in both cross ventilation and illumination.
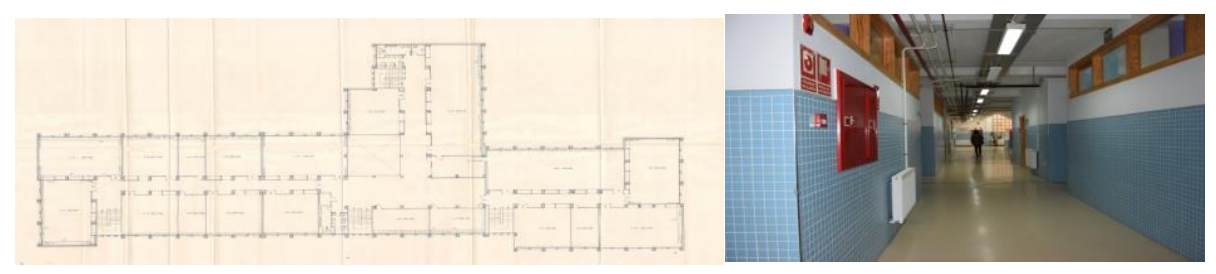

Fig. 1. Typical school building plant distribution. a) left plant, b) right corridor windows.

b) Schools, in special in mild climates, have reduced heating requirements, due to the mild weather and internal gains produced by high density occupation. Nevertheless, ventilation requirements are intense and they are present along the whole school year. Typical heating and ventilation patterns for a Mediterranean school are shown in figure 2.
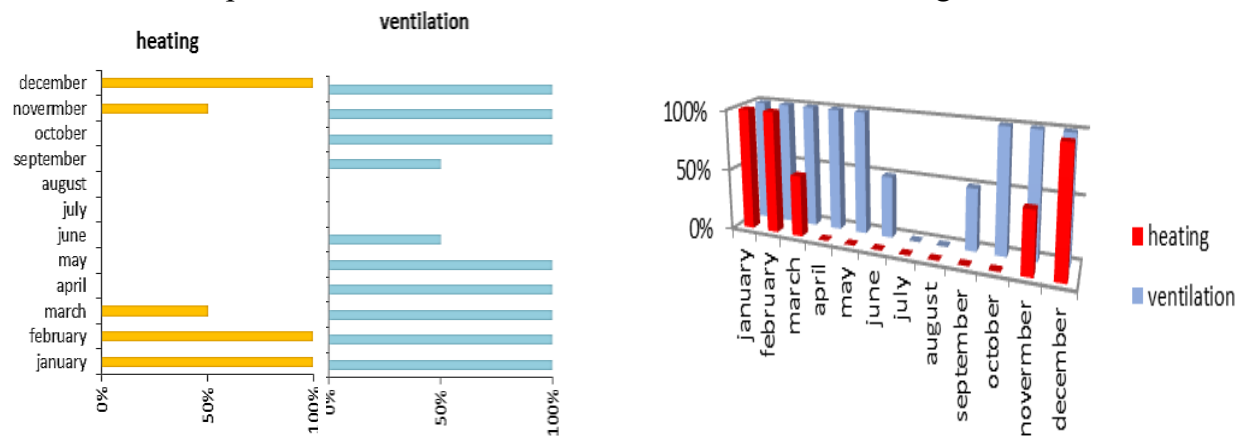

Fig. 2. Mild climate school heating and ventilation patterns. a) Left. Heating profile estimation in terms of heating days percentage by month and ventilation profile estimation in terms of percentage of ventilation days per month. b) Right. Comparison between percent of days per month in which heating and/or ventilation energy requirements for a school in mild climate. 
c) Schools operate half of the year days, around 175 days, with a summer break of 2 months and a half in Spain, and Christmas and Easter holidays. In other countries, where the summer break is shorter, the number of school days is similar. A typical occupation pattern of school occupation in a school of Mediterranean region is presented in fig. 3 (left).

d) Classrooms present non-permanent occupation, due to breaks between lessons, and internal displacements and changes of class into the school building. In figure 3 (right) is shown the variation of occupation profile in classrooms in a Mediterranean school.
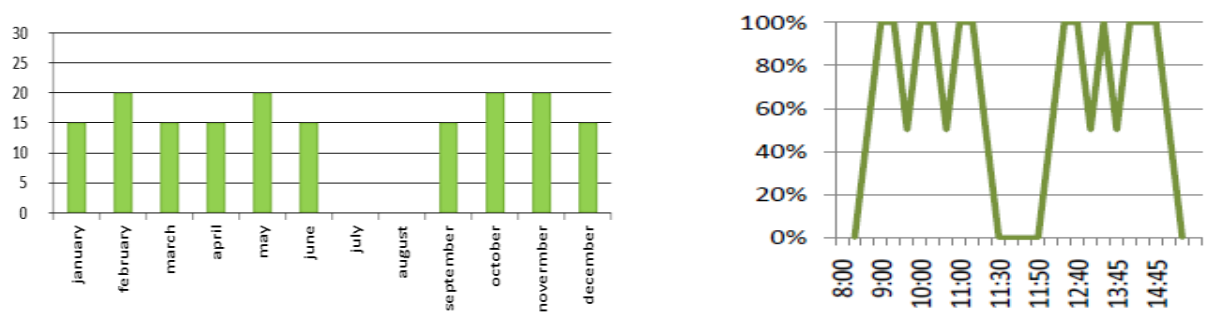

Fig. 3. A) Left. Typical pattern of school days distribution in Mediterranean region as function of the number of days per month B) Right. Occupation rate in a classroom from Monday to Friday.

So, given that all these characteristics define the educational use, determining the way of use and operation of their buildings, so they must be taken into account as basic aspects in the design of buildings and their facilities. In this pathway is interesting CIBSE's School design group publication TM57:2015 Integrated school design [6], with specific recommendations for school buildings.

\section{Indoor environmental quality (IEQ) in schools}

Indoor environmental quality (IEQ) is the result of the thermal, visual, acoustic comfort and indoor air quality (7). Most used Key performance Indicators (KPIs) used to characterize IEQ evolution in the classroom are $\mathrm{CO}_{2}$ level, temperature and humidity.

Indoor Air Quality control in schools is required to ensure the best performance in students and teachers due to time expend indoor. This situation has been studied in different countries, Greece [8-10]. In Serbia, [11] in USA, [12] Denmark and in [14] Portugal. The relationship between ventilation rates and learning is studied in [14] by Clements-Crome et al. considering the occupancy density in classrooms $\left(1.8-2.4 \mathrm{~m}^{2} /\right.$ person) while Toftum et al. analyses in [12] the relationship between ventilation mode and learning outcome.

Pollutants levels were studied in Portuguese case in $[13,15]$ as well as in [10] and its relationship with outdoor air quality. Gennaro et al in [16] analyse different contaminants present indoor and give design recommendations as adequate ventilation systems. Nevertheless, most of these research studies identify IAQ with $\mathrm{CO}_{2}$ levels as an indicator of the bio-effluents in high density occupied spaces $[17,18]$. According to technical regulations, $\mathrm{CO}_{2}$ levels must be below a ppm limit $[19,20]$. In [21], Chenari et al resume values in different countries, being these between 400-1500 ppm, considering EN13779 and SIA 382/1 and DIN 1946-2 standards respectively.

Thermal comfort has been studied specifically in school buildings due to children comfort perception is different to the adults. Romana et al. express thermal comfort definitions [22] in terms of subjective (expresses satisfaction with the thermal environment) and objective condition (looking at the human body as a thermodynamic system that exchanges heat with the surrounding physical environment). In this way, Teli et al. realised in [23] that children perceiving overall comfort is not always related to their thermal state and they suggest that current adult-based comfort standards may not apply to school children. 
Almeida et al. in [24] in Portugal and. Trebilcock et al. in Chile follow the same line [25]. Furthermore Romana et al. in [7], validated Fanger's approach in naturally ventilated Italian classrooms and Dear et al. [26] in Australia studied adaptive thermal comfort in school classrooms showing an acceptable summertime range of temperatures from 19.5 to $26.68^{\circ} \mathrm{C}$.

Therefore, it is necessary to look for a balance between the energy usage to achieve/maintain thermal comfort and the ventilation requirements to guarantee indoor air quality [27]. Sometimes, both conditions are in conflict, with situations as is described in different publications and works, as the ones studied by Wargocki and Wyon [28], Almeida and Freitas [19] or Pereira [29]. For the case of a school building in mild climate, the analysis of ventilation and heating requirements in terms of percent of days per month, figure 2, right, evince that ventilation requirements along the full year for ventilation is around three times global heating requirements.

\section{Thermal and air quality in schools. Actual situation}

Several reviews expose the evidence of inadequate IAQ in schools, as in $[9,11,13,14$, 31-35], and its negative effects on health producing allergic diseases and asthma [15]. Under Wargocki and Wyon research [28], this is due on one hand to the reduced financial resources for the maintenance of systems and inadequate upgrading of school buildings, but in other hand it is also due in warm climates to inadequate air supply and ventilation designs, oriented to preserve energy. Considering that in south Europe and Mediterranean climate, weather conditions are similar and different to north Europe, is necessary to develop specific solutions and standards in order to improve IEQ in schools guaranteeing thermal and quality indoor conditions. Therefore, the application of standards and regulations based on experiences in cold climate regions cannot be applied to new school buildings designs in Mediterranean areas, and the pathway for reaching low-energy or near-zero-energy buildings must be different to avoid unsuitably high temperatures in airtightness highly insulated classrooms. This issue as has been observed in low energy housing in Denmark as showed by Oropeza and Østergaard in [35]. They showed that a dwelling considered as a passive house focused on heating savings presented clear overheating problems during warmer session.

\subsection{Mechanical systems in schools}

The construction standards resulted in less airtightness in buildings constructed in twentieth century. Ventilation was controlled opening doors and windows [7, 24], as way to control contaminant levels in classrooms [37]. In last two decades, the use of mechanical ventilation systems has been extended to achieve IAQ saving heating energy [38] promoted by favourable technical regulations. They integrate heat recovery solutions in order to reduce energy consumptions, as well as night cooling and [38]. Nevertheless, these mechanical systems don't offer in schools the indoor quality expected [39]. In addition, in classrooms because of the high internal heat gains, the heating period is shorter than for other utilizations like residential buildings. Therefore heat recovery will be cost efficient only in very cold regions [5].

With the focus on health, MVS are related with Sick Building Syndrome (SBS). Comparison between natural ventilation and mechanical ventilation in schools were studied in $[12,40]$. Ben-David and Waring studied [41] the impacts of natural versus mechanical ventilation in offices. Pereira et al. in [42] compared risk assessment for airborne infectious diseases between natural ventilation and a split-system air conditioner, concluding that the risk of airborne contagion were much lower opening windows and doors.

From the school buildings point of view in a mild climate as the Mediterranean climate, mechanical systems cannot be the optimal solution. In Portugal Almeida et al describes in 
[30] how even installed these mechanical systems are not being used regularly. The use of MVS in school buildings do not give the expected results in their lifetime due to lack of resources for operation and maintenance and their minor contribution to IAQ.

However, current HVAC regulations in Spain [19] develops a detailed technical framework for MVS to ensure indoor air quality in school buildings. Regulation allows alternative HVAC systems to the mechanical ones but technical framework is not developed yet. It indirectly favours MVS system installation and design against other options that have to give additional steps for certify regulation accomplishment. This situation is similar in other countries as Swiss, as is exposed in [43] or in Portugal, where there are research works in order to improve ventilation energy consumption as Pereira in [29], but natural systems are not considered.

In figure 4 are shown pictures of Mechanical Ventilation Systems in an Andalusian school installed under this regulation. It supposes a relevant capital cost, additional oversized electricity installations for it, including transformers, ducts integration in buildings and maintenance of the whole set of direct and indirect installations.
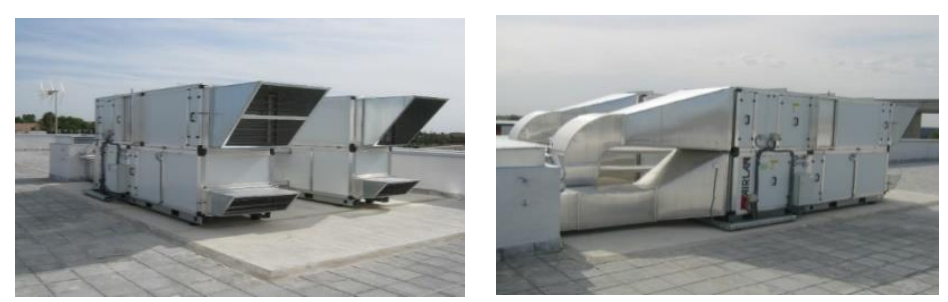

Fig. 4. Mechanical Ventilation system in an Andalusian school. Roof tops.

Therefore it is necessary to seek alternative solutions to ensure Indoor Air Quality within the ambient conditions and specific reality of mild climate schools [28, 39]. Taking into account the set of equipment, the associated capital, operational and maintenance costs and the relative low benefit derived from these systems under real operation of the schools, it is clear the interest of promoting Natural Ventilation Systems in schools applications.

\subsection{NVS in schools}

Several regulations of different countries prescribe natural ventilation systems or at least consider them in designing buildings and schools.

Most important documented experience is shown in UK where the Education Department has published a specific regulation about ventilation in school buildings (BB101) [20]. This document presents natural ventilation as the first solution that must be considered in the design of scholar buildings, while mechanical ventilation systems are considered as the last and non-desirable solution due to investment, operational and maintenance costs and requirements, that can derive in problems related with SBS and other health implications. Besides it has supported the growing of commercial companies with natural ventilation devices specially designed to scholar environment [44-47]. In other countries, NVS are favourite or at least considered to ventilate schools, as in German [48], Australia [49, 50], Ireland [51], and New Zealand [52].

Recent R\&D works in several countries are oriented to assess the effect of using these systems in school buildings design, to guarantee IAQ reducing energy consumption. For example in Italy, Stabile et al. in [38] studied manual airing and Stazi et al. in [54] automatic windows. In Saviese-Switzerland, Flourentzou et al. [55] studied the use of a high stack in comparison with a complex mechanical ventilation system with heat recovery and in 
Thailand, Nitatwichit et al. in [56] studied natural ventilation as well as a cooling passive system.

Different natural ventilation strategies are studied, as Kotani et al present in [56] a review of Cross-Ventilation research papers and stack effect is also studied in [47] with the design of windcatchers for schools. Furthermore in Germany, Hellwig et al. [57] studied the possibility of reactivating historic ventilation stacks. Similar devices were usual in $20^{\text {th }}$ century schools in Andalusia, as is shown in figures 4. However technical design evolution in buildings, evolution of regulatory framework, end user changes of habits, and the lack of experimentation and an adequate knowledge framework supporting design (for this application and climate) have displaced them, with no new building in the last 30 years until 2017 where new ones are under construction.
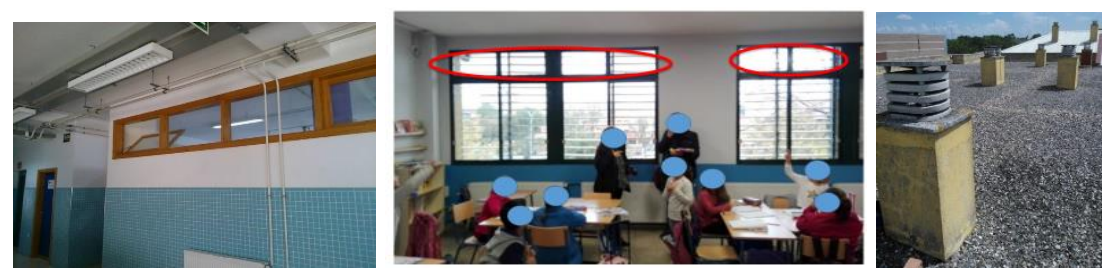

Fig. 5. Left) Cross ventilation in an Andalusian school. Right) Natural Ventilation system in an Andalusian school constructed in 1985.

Considering that, as is seen in [58] air flow depends on window size and position, typical windows design in schools, provides an adequate solution to propose the use of natural ventilation, combining different strategies as cross ventilation and stack effect, as propose Hellwig et al. in [57] reactivating historic ventilation stacks.

Andalusian Government, with more than 4500 schools, is developing a design program in 2017, in which an experimental natural ventilation system in classrooms is under installation in a set of new school buildings in order to prove and validate its operation, to assess their performance, generate new knowledge about the application to schools and give support to the future development of regional technical regulations.

ClimAct project, in the framework of the program Interreg-Sudoe, is in development since June of 2016 to December of 2019. Within this project different strategies to accomplish a transition to a low carbon economy in schools will be analysed. Under this project focus, natural ventilation systems are going to be analysed in school buildings design in Andalusia, Spain, to achieve this goal.

\section{Conclusions}

In this paper natural ventilation systems have been analysed as feasible option to improve the sustainability of buildings in mild climate with special focus on schools. Main derived conclusions applied to schools are:

1. Indoor Air Quality, required to assure the best performance in students and teachers, is controlled with ventilation. Mechanical systems are widely extended using heat recovery systems in order to achieve the efficiency of the HVAC system. In mild climates, requirement of heating is usually lower than for ventilation, so HVAC with heat recovery system could not be the optimal solution to enhance the efficiency of the building. These systems consume electric power in the operation and the internal heat gains can make unnecessary to recover heat. 
2. Natural Ventilation Systems are highlighted as a feasible and sustainable strategy to reduce energy use in buildings. In addition, they can be used for passive cooling strategies with significant energy savings.

3. A Natural Ventilation System present particularities to consider in their design:

- It must be present in first steps of design. They are affected by building location, type of building and dominant winds.

-Window type and its position in the façade is key in the design. In schools, wide windows and windows to corridors are an opportunity to be used in natural ventilation strategies. In addition, cross ventilation and use of stacks can increase ventilation rates.

-There is a clear different thermal subjective perception of children compared with adults standards, so different values should be considered in NVS for schools.

4. Although the interest of Natural Ventilation Systems in school buildings and in Mediterranean and mild climate is collected in an increasing number of publications and $\mathrm{R} \& \mathrm{D}$ works, further research in Mediterranean climate is required, in order to:

- Prove NVS as a strategy to achieve the goal of Zero Energy Buildings, both in schools and other types of buildings.

- It is required further research and testing experiences, differentiated from the developed in Northern countries. It would support the knowledge framework for design criteria and regulatory framework for high density occupation spaces, as schools. Once generated this basis, diffusion of the principles of natural ventilation operation, design constrains and applicability limits and advantages among technical actors, promotors as well as designers, engineers, etc., is a key activity.

- Commercial offer development is a challenge for a greater implantation, to look for, as the example of UK where these systems are highly developed.

\section{Acknowledgments}

This study has been performed as part of the ClimACT project (SOE1/P3/P0429EU) within the Interreg Sudoe Programme, funded by European Regional Development Funds. We acknowledge Andalusian Government and APAE secondary schools by the support and collaboration.

\section{References}

1. E.L.P. Europeo, E.L. Consejo, D.E.L. a Uni, Directiva 2002, 65-71 (2003)

2. Comisión Europea, Bol. Of. L135, 13-35 (2010)

3. ZEMeds, ZEMeds- Promoting renovation of schools in a Mediterranean climate up to nearly Zero-Energy Buildings. www.zemeds.eu, (available at 21/09/2016\%5Cnhttp://www.zemeds.eu/)

4. D.A. Krawczyk, Energy Build. 81, 30-37 (2014)

5. H. Erhorn-kluttig, H. Erhorn, Energy Procedia 48, 1468-1473 (2014)

6. CIBSETM57, Integrated school design (2015)

7. F. Romana, E. Ianniello, B. Igor, Build. Environ. 67, 129-137 (2013)

8. P. Barrett, F. Davies, Y. Zhang, L. Barrett, Build. Environ. 89, 118-133 (2015)

9. K.K. Kalimeri et al., Atmos. Pollut. Res. 7, 1128-1142 (2016)

10. M. Jovanovi, B. Vu, V. Turanjanin, M. Zivkovi, 77, 42-48 (2014)

11. I. Air, T.A. Journal, B. Munksgaard, I. Air, 109-121 (2007)

12. J. Toftum et al., Build. Environ. 92, 494-503 (2015) 
13. P.N. Pegas, et al., 455-468 (2011)

14. A.I.N. Press 43, 362-367 (2008)

15. M. Severo, E. Ramos, J. Madureira, H. Barros, E.D.O. Fernandes, 96, 198-205 (2016)

16. G. De Gennaro, P. Rosario, D. Annamaria, D. Loiotile, 467-482 (2014)

17. L. Chatzidiakou, D. Mumovic, A. Summerfield, (2015), doi:10.1177/0143624414566244

18. V. Turanjanin, B. Vu, M. Jovanovi, N. Mirkov, I. Lazovi, 77, 290-296 (2014)

19. E.Y.T. Ministerio de Industria, 137 (2013).

20. Bb101, Building Bulletin 101 Ventilation of School Buildings (2006)

21. B. Chenari, J. Dias Carrilho, M. Gameiro da Silva, Renew. Sustain. Energy Rev. 59, 1426-1447 (2016)

22. F. Romana, B.W. Olesen, B. Igor, G. Riccio, Energy Build. 81, 326-336 (2014)

23. D. Teli, et al., 3218 (2017), doi:10.1080/09613218.2013.773493

24. R.M.S.F. Almeida, N.M.M. Ramos, V.P. De Freitas, Energy Build. 111, 64-75 (2016)

25. M. Ya, M. Trebilcock, J. Soto-mu, R. F. Martin, 114 (2017), doi:10.1016/j.buildenv.2016.12.036

26. R. De Dear et al., Build. Res. Inf. 0, 1-16 (2017)

27. L. Chatzidiakou, D. Mumovic, A. J. Summerfield, 8975 (2017), doi:10.1080/17508975.2012.725530

28. P. Wargocki, D.P. Wyon, Build. Environ. 59, 581-589 (2013)

29. M.D. Pereira, (2016)

30. R.M.S.F. Almeida, V.P. De Freitas, Energy Build. 81, 127-140 (2014)

31. U. Heudorf, Gesundheitswesen 69, 408-14 (2007)

32. J.T.M. Rosbach et al., 1-10 (2013)

33. J.C. Rufo et al., Porto Biomed. J. 1, 142-146 (2016)

34. J.M. Daisey, W. J. Angell, M. G. Apte

35. M. Turunen, et al., Int. J. Hyg. Environ. Health 217, 733-739 (2014)

36. I. Oropeza-Perez, P.A. Stergaard, Appl. Energy 114, 520-530 (2014)

37. L. Stabile, M. Dell, A. Frattolillo, A. Massimo, A. Russi, Build. Environ. 98, 180-189 (2016)

38. Y. Wang, F.Y. Zhao, J. Kuckelkorn, X.H. Li, H.Q. Wang, Energy Build. 81, 9-17 (2014)

39. R.M.S.F. Almeida, V.P. de Freitas, Energy Procedia 78, 3132-3137 (2015)

40. A.K. Mishra, M. Ramgopal, Build. Environ. 84, 181-188 (2015)

41. T. Ben-David, M.S. Waring, T. Ben-david, M.S. Waring, Build. Environ. 104, 1-17 (2016)

42. M. Luiz, M. Pereira, R. Vilain, A. Tribess, L. Morawska, 1-5 (2015)

43. F. Flourentzou, S. Pantet, (2014)

44. B. Richard, J. Kaiser, S. Abdul, Appl. Energy 92, 606-627 (2012)

45. M. Dehnavi, M. H. Ghadiri, H. Mohammadi, H. Ghadiri, 2, 559-564 (2012)

46. B.M. Jones, R. Kirby, Build. Environ. 44, 1925-1934 (2009)

47. B.M. Jones, R. Kirby, B.M. Jones, R. Kirby, 3315 (2017), doi:10.1080/14733315.2010.11683886 
48. H.-J. Moriske, R. Szewzyk, (available at http://www.umweltbundesamt.de/index-e.htm)

49. Building schools in the 21 st century and Current thinking about learning for a lifetime (2009)

50. I. Division, E. C. Development (2011)

51. G. Document (2009)

52. D. Quality, L. Spaces

53. F. Stazi, F. Naspi, G. Ulpiani, C. Di, Energy Build. 139, 732-746 (2017)

54. F. Flourentzou, S. Pantet, K. Ritz, Int. J. Vent. 0, 1-12 (2017)

55. C. Nitatwichit, Y. Khunatorn, N. Tippayawong, 3839 (2017), doi:10.1080/02533839.2008.9671413

56. H. Kotani, T. Goto, M. Ohba, T. Kurabuchi, 3315 (2017), doi:10.1080/14733315.2009.11683848

57. R. Hellwig, M. Sedlmeier, C. Tanzer, 3315 (2017), doi:10.1080/14733315.2015.11684076

58. P. Heiselberg, E. Bjørn, P. V Nielsen, 3315, 90-100 (2017) 